
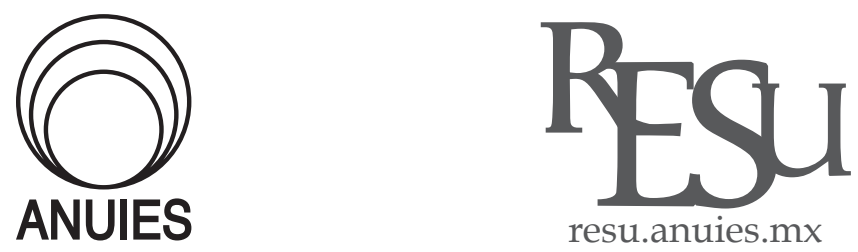

REVITA AEL
EDICACIÓN
SUPERIOR

RESEÑA

\title{
El ethos en la trayectoria de los grupos de investigación científica*
}

Ethos in the trajectory of scientific research groups

\section{Ricardo Félix Grijalva}

* González Quiroz, Julia (2019). Apropiarse de un quehacer: la formación de investigadores en el Departamento de Biología Celular de Cinvestav. México: ANUIES.

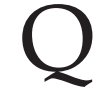
uiero comentar que con esta obra dedicada al ethos en la trayectoria de varios grupos de investigación científica que desarrollan sus actividades en el Departamento de Biología Celular del Centro de Investigación y de Estudios Avanzados (Cinvestav), la autora Julia González cierra un ciclo dentro de un trabajo que comenzó a finales del 2011, como un proyecto desarrollado en el Departamento de Investigaciones Educativas del propio Cinvestav y financiado por el Consejo Nacional de Ciencia y Tecnología. Además de la obra que aquí expongo, algunos de los resultados de la investigación a que hago referencia se han plasmado ya en otro libro coordinado por su mentor, nuestro querido y siempre recordado amigo Eduardo Remedi, y por Rosalba Ramírez: Los científicos y su quehacer. Perspectivas en los estudios sobre trayectorias, producciones y prácticas científicas, también editado por la ANUIES. Me centraré en ciertos aspectos subjetivos que, como partícipe de la investigación que da cuenta la obra, me causó su lectura. Creo que siempre es necesario mirar las cosas con cierta perspectiva y, en su libro, Apropiarse de un quehacer: la formación de investigadores en el Departamento de Biología Celular de Cinvestav, Julia González lo hace muy bien. 
En el primer capítulo, de los cuatro que conforman su trabajo, la autora nos muestra una "radiografía" del Departamento de Biología Celular, que atinadamente nombra "un microcosmos del Cinvestav", dado que en verdad el Departamento de Biología Celular representa muy bien al área biológica de este centro de investigación en su conjunto. Pero es más que una narración del devenir histórico del Departamento pues, para seguir con la misma metáfora médica, se trata de una "historia clínica" completa que incluye desde los antecedentes heredo-familiares hasta el padecimiento actual.

Y es que desde antes de llegar al Departamento de Biología Celular a hacer la investigación sociológica estupendamente plasmada en el libro, Julia González Quiroz ya lo conocía muy bien. Recuerdo perfectamente la vez que nos reunimos con motivo de la primera de las varias entrevistas que me realizó en el laboratorio. Debo confesar que, al inicio, fue un tanto desconcertante para mí el que Julia haya llegado y, de entrada, desplegado en una mesa de mi oficina, al lado mi escritorio, una línea de tiempo con los acontecimientos que de una u otra manera han marcado mi carrera académica, desde mi formación de pregrado hasta la etapa que ella denomina "consolidada". Primero me resultaba extraño pasar de experimentador, que era mi costumbre, a sujeto de investigación, y me parecía también insólito que alguien conociera mi trayectoria de manera tan certera, y no por el hecho de que nunca antes nos hubiésemos visto, lo cual era cierto, sino porque como académico - ya con algunos años de experiencia - había sido sujeto de múltiples evaluaciones curriculares en las que la información siempre había fluido unidireccionalmente, es decir, de mi persona hacia el Comité y, con excepción del siempre escueto dictamen final, nunca había recibido retroalimentación curricular alguna.

Sin embargo, en esa primera entrevista, Julia González Quiroz me subió a una máquina del tiempo y me hizo viajar a lugares físicos que yacían en algún escondite de mi memoria. En ese momento las cosas cambiaron radicalmente, la entrevista fluyó de manera muy natural y la confianza que Julia González inspiró me permitió transmitirle, con emoción y desenfado, mis avatares en el bello oficio de la investigación científica. Con lo anterior he querido simplemente resaltar la preparación y el profesionalismo que González Quiroz ha mostrado a lo largo de su carrera como investigadora social, con sus grandes capacidad y facilidad para realizar el trabajo de campo.

En el segundo capítulo de la obra, la autora analiza la formación de varios de los investigadores del mencionado Departamento y la construcción de su identidad científica a través de plantearse dos preguntas centrales: ¿Cómo se da el proceso de transmisión y apropiación del oficio?, 
y ¿cómo se forja el oficio científico? A mí, alguien ajeno a los temas de la sociología de la educación y de la sociología del conocimiento, me resultó sorprendente y fascinante cómo la autora, a través de una serie de relatos de algunos individuos sobre sus andares por los caminos de la ciencia, puede capturar y analizar de manera tan certera - a través del uso de una serie de elementos teóricos y metodológicos muy bien estructurados - los mecanismos que dan origen y favorecen la evolución de los grupos de investigación estudiados, así como el sentido que dan a sus prácticas individuales y grupales, para finalmente dar luz sobre cómo emerge un orden a partir del ethos del grupo de investigación.

Otro aspecto que me pareció muy relevante en esta sección del libro radica en explorar cómo el aprendizaje trasciende de los maestros a los equipos de investigación. Aquí, el trabajo de Julia González nos muestra con precisión que en la formación para el oficio, además del componente que se adquiere en los textos especializados, existe un elemento intangible que da cuenta, de una manera crítica, de la relación entre el conocimiento y el trabajo científico que se trasmite en el día a día a través del contacto directo entre los miembros del grupo, en las tareas concretas realizadas por sus integrantes en beneficio de la investigación, y en las discusiones sobre cuestiones puntuales de órdenes disciplinar, metodológico u operativo con el líder y demás integrantes del grupo de trabajo.

En los dos capítulos restantes del libro, Julia González analiza y reflexiona el proceso de consolidación de los investigadores y del oficio de hacer ciencia, en donde la exigencia académica es el común denominador. De acuerdo con los resultados de su estudio, la autora concluye atinadamente que la formación de los investigadores apenas inicia cuando obtienen la certificación doctoral. En el Cinvestav, al igual que en otros centros de investigación del país, se fomenta el entrenamiento posdoctoral como un espacio de formación primordial para desarrollar una carrera científica exitosa. Además, identifica la producción de artículos y otros textos científicos como un elemento que articula el trabajo en el laboratorio y establece un vínculo en los procesos de formación y de consolidación de los investigadores.

Aquí, siguiendo la lectura, uno puede considerar no sólo el cambio de la manera de hacer ciencia, en el caso de cada grupo de investigación con el transcurrir de los años, sino que con cierta perspicacia, además, uno puede percatarse cómo se ha ido transformando el panorama nacional de la investigación en su conjunto, a través de la visión de cada uno de los científicos entrevistados. Esto podría constituir parte del "padecimiento actual" retomando la metáfora médica inicial. En algunos pasajes de las 
narraciones, tuve la impresión de que los investigadores con mayor tiempo en el oficio rememoran tiempos pasados con cierta nostalgia y, de algún modo, se refieren a ellos como mejores. Reflexionando sobre el particular, me atrevo a hipotetizar que esto se debe a que la profesionalización de la ciencia ha ido causando una reestructuración en la gestión de la misma, hacia la adopción de un modelo con presupuestos menos generosos y con esquemas burocráticos menos flexibles, basados en un sistema de fiscalización de cifras y de porcentajes que en ocasiones desalienta el espíritu creativo. Por otro lado, si bien este hecho se percibe por todos los involucrados como nocivo para el desarrollo del quehacer científico, implica también que el sistema mantiene viva su relación con los investigadores que tienen varios años de trayectoria $y$, en consecuencia, han acumulado una vasta experiencia, lo cual sin duda constituye una fortaleza del "microcosmos del Cinvestav" estudiado por González Quiroz en términos de la transmisión del conocimiento y la conformación del ethos Mertoniano.

Finalmente, a través de una selección muy meticulosa de fragmentos de las entrevistas, Julia González nos comparte visiones sensibles sobre la historia personal y el recorrido disciplinario de los entrevistados. Aquí, al igual que en el resto del libro, particularmente en la sección donde se reflexiona sobre su responsabilidad de formar a otros, los investigadores se muestran generosos al compartir con la autora su lado más humano y le transmiten una mirada real sobre el quehacer científico, que sin duda ella logra capturar y plasmar a la perfección en su trabajo.

Antes de concluir, quisiera hacer énfasis en la dedicación y el profesionalismo con los cuales Julia González ha conducido su investigación, manteniendo su preocupación por usar los instrumentos del análisis sociológico adecuados en busca de opciones para entender mejor el oficio de científico, y le agradezco que haya escogido al Cinvestav - una institución con una presencia notable en la ciencia de nuestro país - como escenario para este magnífico proyecto de investigación educativa.

Al final me quedo con la idea de que el proceso de consolidación del ethos en realidad corresponde a la expresión de un estilo de vida profesional. Como dice Sylvie Didou, a propósito de la obra de Remedi y Ramírez que mencioné al inicio, la ciencia es, como proceso humano, una cuestión de afectos, de solidaridad, de apertura y de generosidad. Sin duda, ello se puede extrapolar al proceso de transmisión y apropiación del oficio de hacer ciencia como se puede constatar al leer la obra de Julia González Quiroz. 